\title{
Direct Analysis in Real Time by Mass Spectrometric Technique for Determining the Variation in Metabolite Profiles of Cinnamomum tamala Nees and Eberm Genotypes
}

\author{
Vineeta Singh, ${ }^{1}$ Atul Kumar Gupta, ${ }^{1}$ S. P. Singh, ${ }^{2}$ and Anil Kumar ${ }^{1}$ \\ ${ }^{1}$ Department of Molecular Biology \& Genetic Engineering, College of Basic Sciences and Humanities, \\ G. B. Pant University of Agriculture and Technology, Uttarakhand, Pantnagar 263145, India \\ ${ }^{2}$ Department of Pharmacology \& Toxicology, College of Veterinary Science, \\ G. B. Pant University of Agriculture and Technology, Uttarakhand, Pantnagar 263145, India
}

Correspondence should be addressed to Anil Kumar, anilkumar.mbge@gmail.com

Received 15 March 2012; Accepted 4 April 2012

Academic Editors: T. Hatano, P. Kittakoop, and J. Shiea

Copyright (C) 2012 Vineeta Singh et al. This is an open access article distributed under the Creative Commons Attribution License, which permits unrestricted use, distribution, and reproduction in any medium, provided the original work is properly cited.

\begin{abstract}
Cinnamomum tamala Nees \& Eberm. is an important traditional medicinal plant, mentioned in various ancient literatures such as Ayurveda. Several of its medicinal properties have recently been proved. To characterize diversity in terms of metabolite profiles of Cinnamomum tamala Nees and Eberm genotypes, a newly emerging mass spectral ionization technique direct time in real time (DART) is very helpful. The DART ion source has been used to analyze an extremely wide range of phytochemicals present in leaves of Cinnamomum tamala. Ten genotypes were assessed for the presence of different phytochemicals. Phytochemical analysis showed the presence of mainly terpenes and phenols. These constituents vary in the different genotypes of Cinnamomum tamala. Principal component analysis has also been employed to analyze the DART data of these Cinnamomum genotypes. The result shows that the genotype of Cinnamomum tamala could be differentiated using DART MS data. The active components present in Cinnamomum tamala may be contributing significantly to high amount of antioxidant property of leaves and, in turn, conditional effects for diabetic patients.
\end{abstract}

\section{Introduction}

The genus Cinnamomum belonging to the family Lauraceae comprises 270 species which occur naturally in Asia and Australia. About 20 species occur in India. The etymology is derived from the Greek word "Kinnamomon" (meaning spice). The Greeks borrowed the word from Phoenicians, indicating that they traded with the East from early times. The specific epithet "tamala" is after a local name of the plant in India. Cinnamomum tamala Nees and Eberm. is an evergreen, medium-sized tree (attaining 8-12 meters height and a girth of $150 \mathrm{~cm}$ ), found in India along the North-Western Himalayas, in Sikkim, Assam, Mizoram, and Meghalya [1]. It is also found in tropical and subtropical Asia, Australia, Pacific region, and South Asia $[2,3]$. It is distributed from near Indus to Bhutan [4]. Natural stands of C. tamala are mostly found in shady moist habitats. The leaves, known as tejpat, tejpatta, or tejpata in Hindi, tamalpatra in Marathi, and Indian Cassia in English, are usually olive green in color, may have some brownish spots and have three veins down the length of the leaf. The leaves of Cinnamomum tamala are used extensively in the cuisines of India (particularly in the Moghul cuisine of North India) and as spice in the food industry because of its special aroma [5], that is, clove-like-taste and pepper like odour. It also acts as an insect repellent. In Kashmir they are used as a substitute for paan (betel leaves). It is also used in industries as fragrance component in soaps, detergents, cosmetics and perfumes, and toothpastes. The leaves of this tree have medicinal properties and are used in treatment of numerous ailments $[6,7]$. It is used as food, fodder, medicine, and timber in Uttarakhand Himalayan region [8]. 
Ayurveda describes the use of leaves of tejpatta in the treatment of ailments such as anorexia, bladder disorders, dryness of mouth, coryza, diarrhoea, nausea, and spermatohoea [7]. The leaf of C. tamala is a brain tonic, antihelminthic, diuretic, is good for the liver and spleen and is useful in inflammation. Its bark is useful for the treatment of gonorrhoea [9]. Besides these, various pharmacological activities have been detected in natural products from Cinnamomum species. The essential oil from Cinnamomum tamala exhibits antifungal $[10,11]$, antibacterial [12], antidermatophytic [13], antihypercholesterolaemic, and antihyperglycaemic effects [14]. It is also used medicinally as a carminative, an anti flatulent, a diuretic, and in the treatment of cardiac disorders [3], analgesic in dental preparations [15-17] due to presence of eugenol (4-hydroxy3-methoxy allylbenzene). Different extracts from leaves of C. tamala have shown antiinflammatory [18], antioxidant [19], antiulcer [20], anticarcinogenic [21], antidiarrhoeal [22] effects, antidiabetic $[23,24]$ which is mainly contributed by Cinnamaldehyde (3-phenyl-2- propenal), a potential antidiabetic agent [25].

Essential oil extracted from the leaves contains majorly polyphenols, monoterpenoids, and sesquiterpenoids including phellandrene, eugenol, linalool, and some traces of $\alpha$ pinene, $\mathrm{p}$-cymene, $\beta$-pinene and phenylpropanoids [26], camphene, cinnamyl acetate, camphor, $\beta$-caryophyllene, [27, $28]$, myrcene, limonene $[29,30]$. Two chemotypes of $C$. tamala were reported, namely, cinnamaldehyde type and eugenol type [31]. Leaves contain essential oil (Eugenol and Isoeugenol), and bark contains $70-80 \%$ cinnamic aldehyde.

Direct Analysis in Real Time (DART) is an atmospheric pressure that instantaneously ionizes gases, liquids and solids in open air under ambient conditions. Direct Analysis in Real Time (DART) has been coupled to the AccuTOF atmospheric pressure ionization mass spectrometer to permit high-resolution, exact mass measurements of gases, liquids, and solids [32]. DART is based on the atmospheric pressure interactions of long-lived electronic excited-state atoms or vibronic excited-state molecules with the sample and atmospheric gases. It was among the first ambient ionization techniques not requiring any sample preparation, as ionization can take place directly on the sample surface so plant products can be analyzed directly without any sample preparation [33-35]. In view of the ease with which natural products can be analyzed by DART MS, it was thought that DART MS could be a suitable tool for the chemical profiling of the different landraces of Cinnamomum tamala leaves. The presence of phytochemicals can easily be assessed so that the leaves can further be scientifically validated and can be used for combating against the dreadful disease like diabetes.

\section{Material and Methods}

2.1. Collection of Sample. Seven cultivars were procured from IISR Calicut, namely, A11, A12, B12, C1, C2, C3, D11, all from northeast, and three were collected from north Uttarakhand, namely, UM, UC, UH as indicated in

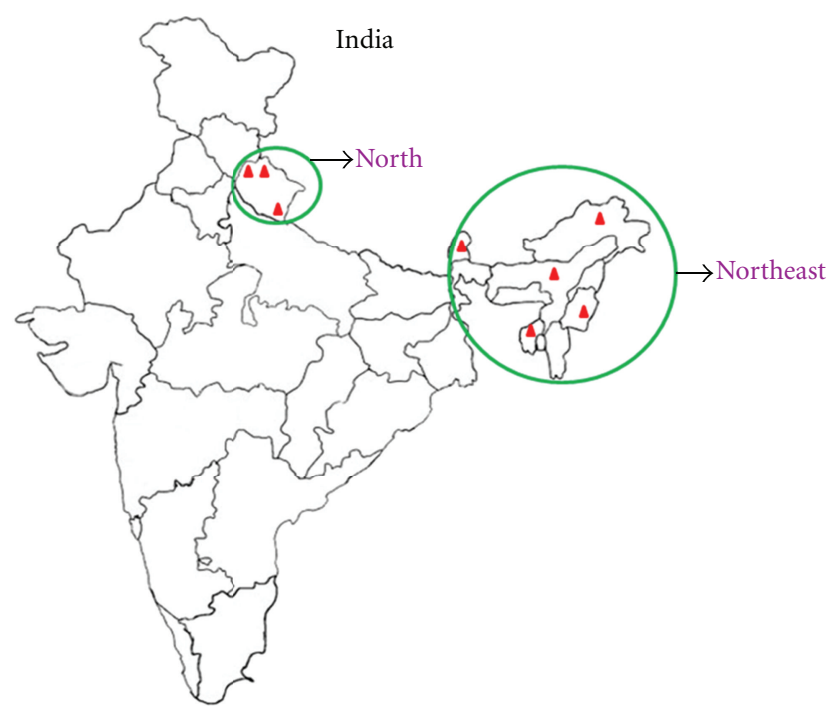

FIGURE 1: India's map representing the area (Northeast and North) marked by green circle from where the Cinnamomum genotypes were procured.

Figure 1. The leaf samples were of mature stage and were collected in the month of Feburary.

2.2. Instrumentation. The mass spectrometer used was a JMS 100 TLC (Accutof) atmospheric pressure ionization time of flight mass spectrometer (Jeol, Tokyo, Japan) fitted with a DART ion source. The mass spectrometer was operated in positive ion mode with resolving power of 6000 (full width at half maximum). The orifice 1 potential was set to $15 \mathrm{~V}$, resulting in minimal fragmentation. The ring lens and orifice 2 potential were set to 13 and $5 \mathrm{~V}$, respectively. Orifice 1 was set to a temperature of $100^{\circ} \mathrm{C}$. The RF ion guide potential was $300 \mathrm{~V}$. The DART ion source was operated with helium gas flowing at approximately $4.0 \mathrm{~L} / \mathrm{min}$. The gas heater was set to $300^{\circ} \mathrm{C}$. The potential on the discharge needle electrode of the DART source was set to $3000 \mathrm{~V}$, electrode 1 was $100 \mathrm{~V}$ and the grid was at $250 \mathrm{~V}$. Freshly cut pieces of $C$. tamala were positioned in the gap between the DART source and mass spectrometer for measurements. Data acquisition was from $\mathrm{m} / \mathrm{z} 50.0$ to 1000.0. Exact mass calibration was accomplished by including a mass spectrum of neat polyethylene (PEG) glycol (1:1 mixture PEG 200 and PEG 600) in the data file. m-Nitrobenzyl alcohol was also used for calibration. The mass calibration was accurate to within $0.002 \mathrm{u}$. Using the Mass Center software, the elemental composition could be determined on selected peaks.

2.3. Statistical Analysis. Triplicate samples of each land race were subjected for DART analysis, and results were reproducible. PCA analysis was carried out using JMP 8.0 statistical analysis software. 

Ionization mode: ESI+
MS calibration name: YOKUDELNA_ES+_2000
Orificel volt sweep: $15 \mathrm{~V}$
Experiment date/time: 6/14/2011 3:30:56 PM
Ring lens volt: $11 \mathrm{~V}$
Time of maximum: $0.389 \mathrm{~min}$
Operator name: admin

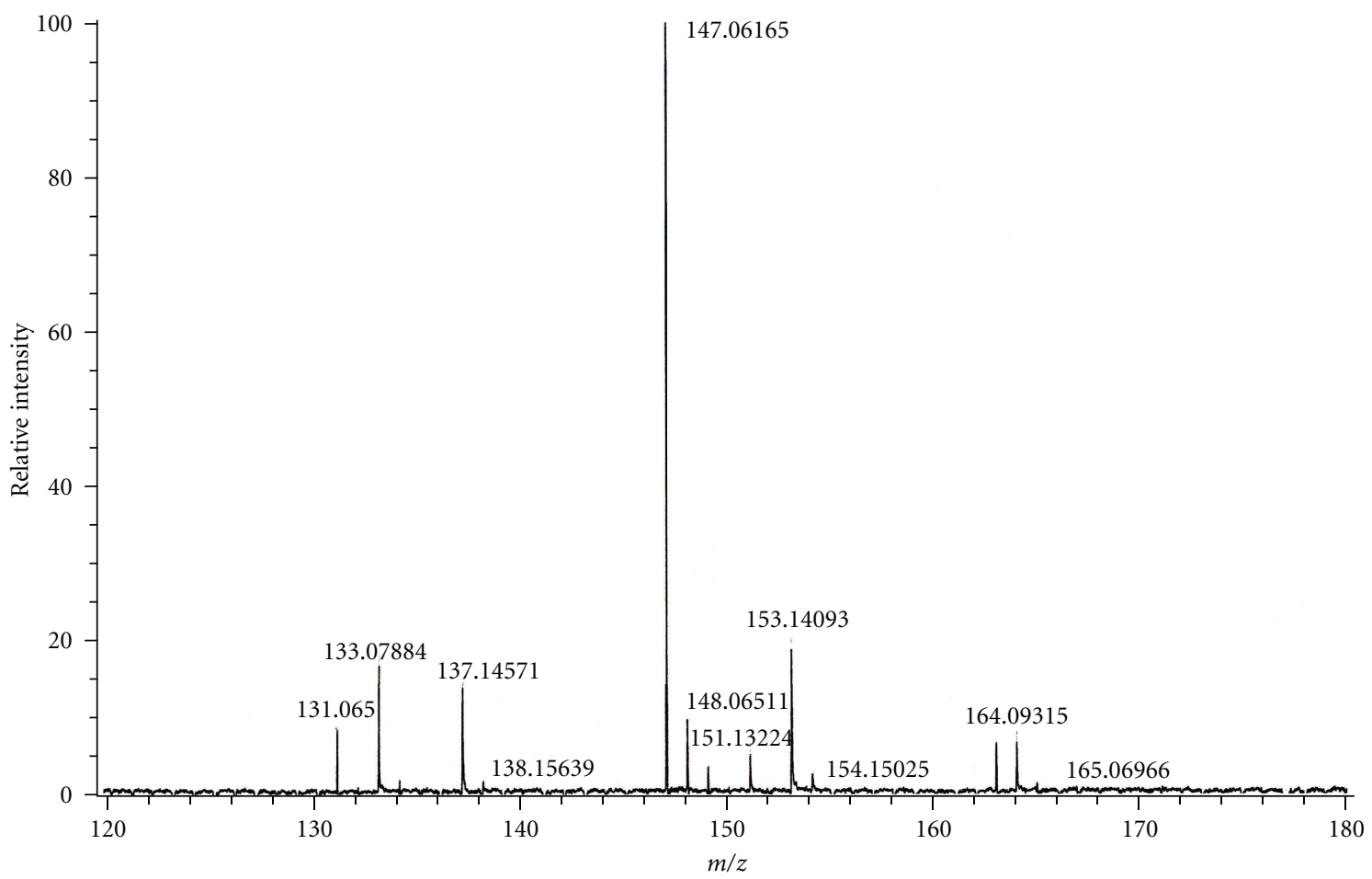

Figure 2: DART MS C. tamala leaf of the genotype A11.

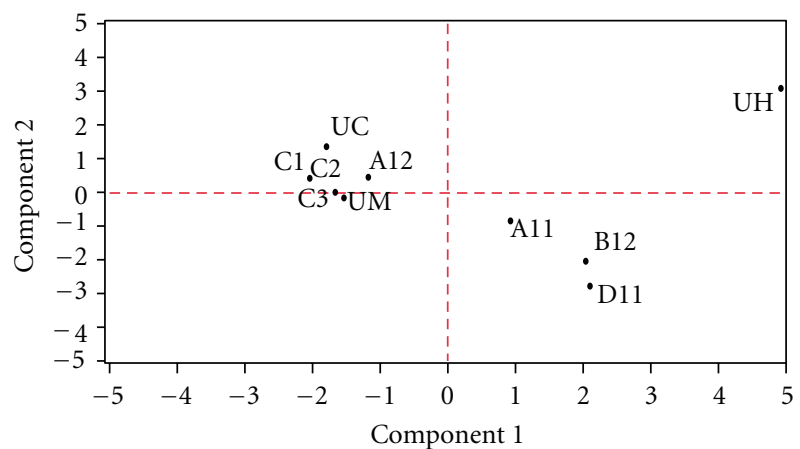

FIgURE 3: PCA score plot of the abundances of the various ions in the DART mass spectra of the leaves of various Cinnamomum genotypes.

\section{Result and Discussion}

Cinnamomum tamala leaves mainly consist of a number of polyphenols and terpenoids. The compounds reported in plants are listed in Table 1.

The presence of these compounds in different genotypes procured from IISR Calicut (A11, A12, B12, C1, C2, C3, D11) and collected from Uttarakhand (UM, UC, UH) was analysed successfully through DART MS. A representative DART MS of Cinnamomum tamala is given in Figure 2.

The DART MS showed the presence of peak m/z 164 which correspond to the major constituent eugenol in leaves of all the ten genotypes. The result was corresponded with another study in which chemotype of Cinnamomum tamala leaf oil rich in eugenol was reported from Northeast India [36]. Isoforms of eugenol, that is, methyl eugenol and eugenol acetate showed peak at m/z 178 and 206, respectively. The peak of $\mathrm{m} / \mathrm{z} 132$, the peak of cinnamaldehyde, was observed in A11, B12, D11, UH, and UC. This was in contrast to study of Bradu and Sobti [37] who reported cinnamaldehyde as major constituents of Cinnamomum tamala leaf oil. Some of the derivatives of cinnamaldehyde were present showing peak at m/z 148 and 176. Presence of certain naturally occurring monoterpenoids and sesquiterpenoids in these genotypes was also observed. Peak m/z at 154 which could be attributed due to linalool was observed only in $\mathrm{A} 12, \mathrm{~B} 12$, and D11. Besides this peak of other terpenes was observed at m/z, 126, 166, 180 corresponding to 6-Methyl-5heptene- 2 one, ethyl vanillin, coniferyl alcohol, respectively. Since some of the terpenes have same molecular weight, it was not possible to distinguish them from DART MS alone. The peak at m/z 150 could be due to carvone, carvacrol, or p-cymene-8-ol, and peak at $\mathrm{m} / \mathrm{z} 136$ could be of $\alpha$ pinene, camphene, myrcene, limonene, phellandrene. Since 
TABLE 1: Exact mass data from the DART mass spectra of Cinnamomum tamala.

\begin{tabular}{|c|c|c|c|c|}
\hline $\begin{array}{l}\text { Molecular } \\
\text { weight }\end{array}$ & $\begin{array}{c}\text { Measured } \\
\text { mass }\end{array}$ & $\begin{array}{c}\text { Calculated } \\
\text { mass }\end{array}$ & $\begin{array}{l}\text { Molecular } \\
\text { formula }\end{array}$ & Remarks \\
\hline 132 & 131.06500 & 132.15922 & $\mathrm{C}_{9} \mathrm{H}_{8} \mathrm{O}$ & Cinnamaldehyde \\
\hline 134 & 133.07884 & 134.21816 & $\mathrm{C}_{10} \mathrm{H}_{14}$ & p-cymene \\
\hline 136 & 135.14386 & 136.23404 & $\mathrm{C}_{10} \mathrm{H}_{16}$ & $\begin{array}{l}\alpha \text {-pinene, Camphene, } \\
\text { Myrcene, limonene, } \\
\text { phellandrene }\end{array}$ \\
\hline 148 & 148.06511 & 148.15862 & $\mathrm{C}_{9} \mathrm{H}_{8} \mathrm{O}_{2}$ & Cinnamic acid \\
\hline 150 & 150.13288 & 150.21756 & $\mathrm{C}_{10} \mathrm{H}_{14} \mathrm{O}$ & Carvone, p-cymene-8-ol \\
\hline 152 & 151.13224 & 152.23344 & $\mathrm{C}_{10} \mathrm{H}_{16} \mathrm{O}$ & camphor \\
\hline 154 & 154.15025 & 154.24932 & $\mathrm{C}_{10} \mathrm{H}_{18} \mathrm{O}$ & Linalool, 1,8 cineole \\
\hline 164 & 164.09315 & 164.20108 & $\mathrm{C}_{10} \mathrm{H}_{12} \mathrm{O}_{2}$ & Eugenol \\
\hline 176 & 175.09068 & 176.21178 & $\mathrm{C}_{11} \mathrm{H}_{12} \mathrm{O}_{2}$ & Cinnamyl acetate \\
\hline 178 & 177.13526 & 178.22766 & $\mathrm{C}_{11} \mathrm{H}_{14} \mathrm{O}_{2}$ & Methyl eugenol \\
\hline 206 & 205.22984 & 206.23776 & $\mathrm{C}_{12} \mathrm{H}_{14} \mathrm{O}_{3}$ & Eugenol acetate \\
\hline 220 & 220.13956 & 220.35046 & $\mathrm{C}_{15} \mathrm{H}_{24} \mathrm{O}$ & $\beta$-caryophyllene oxide \\
\hline
\end{tabular}

TABle 2: DART mass spectral data of A11 (1), A12 (2), B12 (3), C1 (4), C2 (5), C3 (6), D11 (7), UM (8), UC (9), UH (10) cultivars of Cinnamomum tamala leaves.

\begin{tabular}{|c|c|c|c|c|c|c|c|c|c|c|}
\hline \multirow{2}{*}{$\mathrm{m} / \mathrm{z}$} & \multicolumn{10}{|c|}{ Cinnamomum tamala genotypes } \\
\hline & A11 & A12 & $\mathrm{B} 12$ & $\mathrm{C} 1$ & $\mathrm{C} 2$ & $\mathrm{C} 3$ & D11 & UM & UC & $\mathrm{UH}$ \\
\hline 127 & - & - & + & - & + & + & - & + & + & + \\
\hline 131 & + & - & + & - & - & - & + & - & + & + \\
\hline 132 & + & - & + & - & - & - & + & - & + & + \\
\hline 133 & + & - & + & - & - & - & + & - & + & + \\
\hline 135 & - & - & + & - & - & - & + & - & + & + \\
\hline 137 & + & - & + & - & + & - & + & - & + & + \\
\hline 145 & - & - & + & + & + & + & + & + & + & + \\
\hline 147 & + & - & + & - & - & - & + & - & - & + \\
\hline 148 & + & - & + & - & - & - & + & - & - & + \\
\hline 150 & + & + & + & & & + & + & & + & + \\
\hline 151 & + & - & + & - & - & - & + & - & - & + \\
\hline 153 & + & - & + & - & - & - & + & - & - & + \\
\hline 154 & + & - & + & - & - & - & + & - & - & + \\
\hline 163 & + & + & + & + & + & + & + & + & + & + \\
\hline 164 & + & + & + & + & + & + & + & + & + & + \\
\hline 165 & + & + & + & + & + & + & + & - & + & + \\
\hline 166 & & + & + & + & + & + & & & + & + \\
\hline 175 & - & - & + & - & - & - & - & - & - & + \\
\hline 177 & - & - & + & - & - & - & - & - & - & + \\
\hline 180 & - & + & + & + & + & + & - & + & + & + \\
\hline 193 & + & + & + & - & + & + & & + & + & + \\
\hline 205 & - & - & + & - & - & - & - & - & + & - \\
\hline 220 & - & - & + & - & - & - & + & - & + & - \\
\hline 287 & - & + & + & - & - & - & - & + & - & + \\
\hline 293 & + & - & + & - & - & - & + & - & - & + \\
\hline 445 & + & + & + & + & + & + & + & + & + & + \\
\hline 447 & + & + & + & + & + & + & + & + & + & + \\
\hline 448 & + & + & + & + & + & + & + & + & + & + \\
\hline 449 & + & + & + & + & + & + & + & + & + & + \\
\hline
\end{tabular}

+ Present, -Absent. 
they have the same molecular formula, a distinction could not be made. These differences in the spectra of the different cultivars are shown in Table 2.

It is not easy to identify and differentiate all the components independently based on their mass spectral data. MS base chemical profiling generates complex data sets which need sophisticated software to enable interpretation. Visualization is a key aspect as the data contained a number of variables. PCA is an indirect ordination technique for obtaining a low-dimensional representation of multivariate data so that the data can be explored visually in a twodimensional PCA correlation biplot and any structure in the data identified. PCA groups the samples solely on information on the measured data and does not need any extra knowledge about the sample and therefore can be used to summarize and visualize the structure of the data. The mass spectral data for all the ten cinnamomum leaves were subjected to PCA using 12 variables (abundances at $\mathrm{m} / \mathrm{z} 132,134,136,148,150,152,154,164,176,178,206$, 220). The PCA score plot clearly brings out the relationship among all the cinnamomum data, and all the ten sets are clearly separated (Figure 3). It seems that genotype $\mathrm{UH}$ is completely different from all other genotypes whereas A11, $\mathrm{B} 12$, and D11 are found to have similarity. Rest six genotypes (C1, C2, C3, UM, A12, and UC) are much closer to each other. It is evident from the study that PCA effectively served the purpose and all the cinnamomum genotypes could be differentiated by this method.

\section{Conclusion}

The combination of ion source with a high-resolution timeof-flight mass spectrometer permits rapid qualitative and quantitative analysis of a wide variety of materials. The DART MS of the leaves of cinnamomum tamala could be recorded without any kind of sample preparation. The abundances of the characteristics phenols and terpenes were different in all the ten genotypes. Although peak corresponding to cinnamaldehyde was observed in some of the genotypes, the presence of eugenol was assessed in almost all the genotypes. This compound may be responsible for highest amount of antioxidant activity of the plant which may be enhanced due to the synergestic effect of different kind of terpenes present. Therefore the plant can be used to combat the diseases including diabetes caused by different oxidative stress. PCA showed the expected grouping of genotypes.

\section{Abbreviations}

DART: Direct analysis in real time

PCA: Principal component analysis

TOF: Time of flight.

\section{Acknowledgments}

Grateful acknowledgement is made to Dr. B. Krishnamoorthy, IISR Calicut, for providing the authors with the different genotypes of northeast. Acknowledgment is also due to Dr. Brijesh Kumar and Mr. Vikas Bajpai, Sophisticated Analytical Instrument Facility, CDRI (CSIR), Lucknow where the mass spectrometric studies were carried out.

\section{References}

[1] G. Sharma and A.R. Nautiyal, "Cinnamomum tamala: a valuable tree of Himalayas," International Journal of Medicinal and Aromatic Plants, vol. 1, no. 1, pp. 1-4, 2011.

[2] D. Brandis, Indian Trees: An Account of Trees, Shrubs, Woody Climbers, Bamboos and Palm Indigenous or Commonly Cultivated in the British Indian Empir, Bishen Singh Mahendra Pal Singh, Dehradun, India, 1998.

[3] S. R. Mir, M. Ali, and R. Kapoor, "Chemical composition of essential oil of Cinnamomum tamala Nees et Eberm. leaves," Flavour and Fragrance Journal, vol. 19, no. 2, pp. 112-114, 2004.

[4] J. D. Hooker, The Flora of British India, vol. 5, Bishen Singh Mahendra Pal Singh, Dehradun, India, 1988.

[5] S. T. Chang and S. S. Cheng, "Antitermitic activity of leaf essential oils and components from Cinnamomum osmophleum," Journal of Agricultural and Food Chemistry, vol. 50, no. 6, pp. 1389-1392, 2002.

[6] A. Kar, B. K. Choudhary, and N. G. Bandyopadhyay, "Comparative evaluation of hypoglycaemic activity of some Indian medicinal plants in alloxan diabetic rats," Journal of Ethnopharmacology, vol. 84, no. 1, pp. 105-108, 2003.

[7] L. D. Kapoor, CRC Handbook of Ayurvedic Medicinal Plants, CRC Press, Boca Raton, Fla, USA, 2000.

[8] S. Nautiyal and H. Kaechele, "Adverse impacts of pasture abandonment in Himalayan protected areas: testing the efficiency of a natural resource management plan (NRMP)," Environmental Impact Assessment Review, vol. 27, no. 2, pp. 109-125, 2007.

[9] K. R. Kirtikar and B. D. Basu, Indian Medicinal Plants, vol. 2, Lalit Mohan Basu, Ahmadabad, India, 2nd edition, 1981.

[10] B. Srivastava, A. Sagar, and N. K. Dubey, "Evaluation of Cinnamomum tamala oil and its phenylpropanoid eugenol for their antifungal and antiaflatoxigenic activity," Food Analytical Methods, vol. 4, no. 3, pp. 347-356, 2011.

[11] P. Baruah, R. K. Sharma, R. S. Singh, and A. C. Ghosh, "Fungicidal activity of some naturally occurring essential oils against Fusarium moniliforme," Journal of Essential Oil Research, vol. 8, no. 4, pp. 411-412, 1996.

[12] P. Goyal, A. Chauhan, and P. Kaushik, "Laboratory evaluation of crude extracts of Cinnamomum tamala for potential antibacterial activity," Electronic Journal of Biology, vol. 5, no. 4, pp. 75-79, 2009.

[13] P. Yadav, N. K. Dubey, V. K. Joshi, J. P. N. Chansouria, and P. Yadav, "Anti-dermatophytic activity of essential oil of Cinnamomum," Journal of Medicinal and Aromatic Plant Sciences, vol. 21, pp. 347-351, 1999.

[14] S. R. Sharma, S. K. Dwivedi, and D. Swarup, "Hypoglycaemic and hypolipidemic effects of Cinnamomum tamala Nees leaves," Indian Journal of Experimental Biology, vol. 34, no. 4, pp. 372-374, 1996.

[15] I. U. Fischer and H. J. Dengler, "Sensitive high-performance liquid chromatographic assay for the determination of eugenol in body fluids," Journal of Chromatography, vol. 525, no. 2, pp. 369-377, 1990.

[16] S. Kermasha, M. Goetghebeur, and J. Dumont, "Separation and characterization of pepper-contaminated cinnamon 
Using HPLC analyses," Lebensmittel-Wissenschaft and Technologie, vol. 27, no. 6, pp. 578-582, 1994.

[17] M. Yuwono, Siswandono, A. F. Hafid et al., "Eugenol," Analytical Profiles of Drug Substances and Excipients, vol. 29, pp. 149-177, 2002, Academic Press, Elsevier Science (USA).

[18] M. Gambhire, A. R. Juvekar, and S. S. Wankhede, "Antiinflammatory activity of aqueous extract of Cinnamomum tamala leaves by in vivo and in vitro methods," Journal of Pharmacy Research, vol. 2, no. 9, pp. 1521-1524, 2009.

[19] V. Gupta and M. Sharma, "Protective effect of Cinnamomum tejpata on lipid peroxide formation in isolated rat liver homogenate," Current Research Journal of Biological Sciences, vol. 2, no. 4, pp. 246-249, 2010.

[20] M. B. Eswaran, S. Surendran, M. Vijayakumar, S. K. Ojha, A. K. S. Rawat, and C. V. Rao, "Gastroprotective activity of Cinnamomum tamala leaves on experimental gastric ulcers in rats," Journal of Ethnopharmacology, vol. 128, no. 2, pp. 537$540,2010$.

[21] A. R. Rao and S. Hashim, "Chemopreventive action of oriental food-seasoning spices mixture Garam masala on DMBAinduced transplacental and translactational carcinogenesis in mice," Nutrition and Cancer, vol. 23, no. 1, pp. 91-101, 1995.

[22] C. V. Rao, M. Vijayakumar, K. Sairam, and V. Kumar, "Antidiarrhoeal activity of the standardised extract of Cinnamomum tamala in experimental rats," Journal of Natural Medicines, vol. 62, no. 4, pp. 396-402, 2008.

[23] R. Kumanan, S. Manimaran, S. Khan, S. P. Dhanabal, and M. J. Nanjan, "Screening of bark of Cinnamomum tamala (Lauraceae) by using $\alpha$-amylase inhibition assay for antidiabetic activity," International Journal of Pharmaceutical and Biomedical Research, vol. 1, no. 2, pp. 69-72, 2010.

[24] U. Chakraborty and H. Das, "Antidiabetic and antioxidant activities of Cinnamomum tamala leaf extracts in Stz-treated diabetic rats," Global Journal of Biotechnology \& Biochemistry, vol. 5, no. 1, pp. 12-18, 2010.

[25] P. Subash Babu, S. Prabuseenivasan, and S. Ignacimuthu, "Cinnamaldehyde-A potential antidiabetic agent," Phytomedicine, vol. 14, no. 1, pp. 15-22, 2007.

[26] M. Shah and M. Panchal, "Ethnopharmacological properties of Cinnamomum tamala-a review," International Journal of Pharmaceutical Sciences Review and Research, vol. 5, no. 3, pp. 141-144, 2010.

[27] V. C. Pawar and V. S. Thaker, "in vitro efficacy of 75 essential oils against Aspergillus niger,” Mycoses, vol. 49, no. 4, pp. 316323, 2006.

[28] R. O. B. Wijesekera, A. L. Jayewardene, and L. S. Rakapakse, "Volatile constituents of leaf, stem and root oils of cinnamon (Cinnamomum zeylanicum)," Journal of the Science of Food and Agriculture, vol. 25, pp. 1211-1220, 1974.

[29] R. L. Smith, T. B. Adams, J. Doull et al., "Safety assessment of allylalkoxybenzene derivatives used as flavouring substancesmethyl eugenol and estragole," Food and Chemical Toxicology, vol. 40, no. 7, pp. 851-870, 2002.

[30] F. Siano, C. Ghizzoni, F. Gionfriddo, E. Colombo, L. Servillo, and D. Castaldo, "Determination of estragole, safrole and eugenol methyl ether in food products," Food Chemistry, vol. 81, no. 3, pp. 469-475, 2003.

[31] A. Hussain, O. P. Viramani, A. Sharma, A. Kumar, and L. N. Misra, Major Essential Oil-bearing Plants of India, CIMAP, Lucknow, India, 1988.

[32] R. B. Cody, J. A. Laramée, and H. D. Durst, "Versatile new ion source for the analysis of materials in open air under ambient conditions," Analytical Chemistry, vol. 77, no. 8, pp. 22972302, 2005.
[33] O. P. Haefliger and N. Jeckelmann, "Direct mass spectrometric analysis of flavors and fragrances in real applications using DART," Rapid Communications in Mass Spectrometry, vol. 21, no. 8, pp. 1361-1366, 2007.

[34] K. P. Madhusudanan, S. Banerjee, S. P. S. Khanuja, and S. K. Chattopadhyay, "Analysis of hairy root culture of Rauvolfia serpentina using direct analysis in real time mass spectrometric technique," Biomedical Chromatography, vol. 22, no. 6, pp. 596-600, 2008.

[35] H. J. Kim and Y. P. Jang, "Direct analysis of curcumin in turmeric by DART-MS," Phytochemical Analysis, vol. 20, no. 5, pp. 372-377, 2009.

[36] S. C. Nath, A. Baruah, and A. K. Hazarika, "Essential oils of the leaves of Cinnamomum Schaefer members," Indian Perfumer, vol. 43, pp. 473-478, 1999.

[37] B. L. Bradu and S. N. Sobti, "Cinnamomum tamala in North West Himalayas; evaluation of various chemical types for perfumery value," Indian Perfumer, vol. 32, pp. 334-340, 1988. 


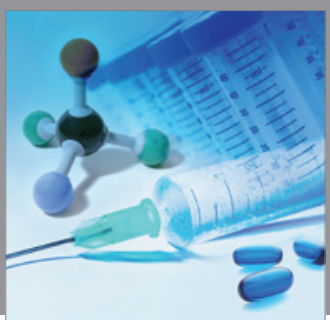

International Journal of

Medicinal Chemistry

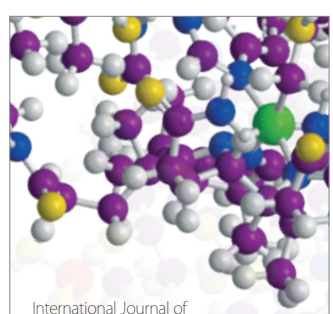

Carbohydrate Chemistry

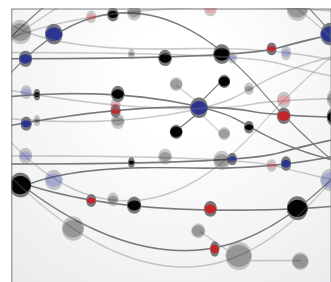

The Scientific World Journal
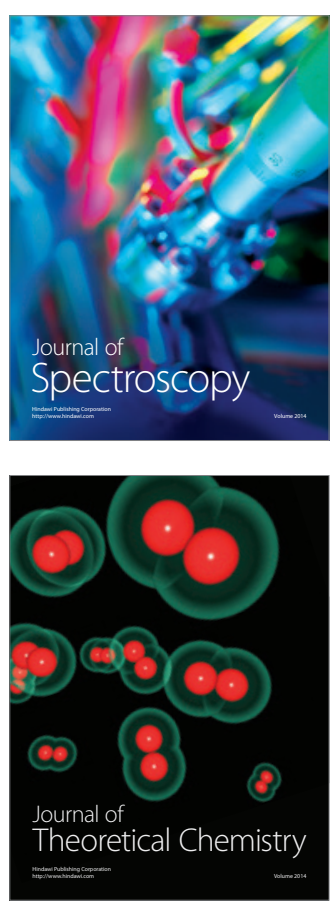
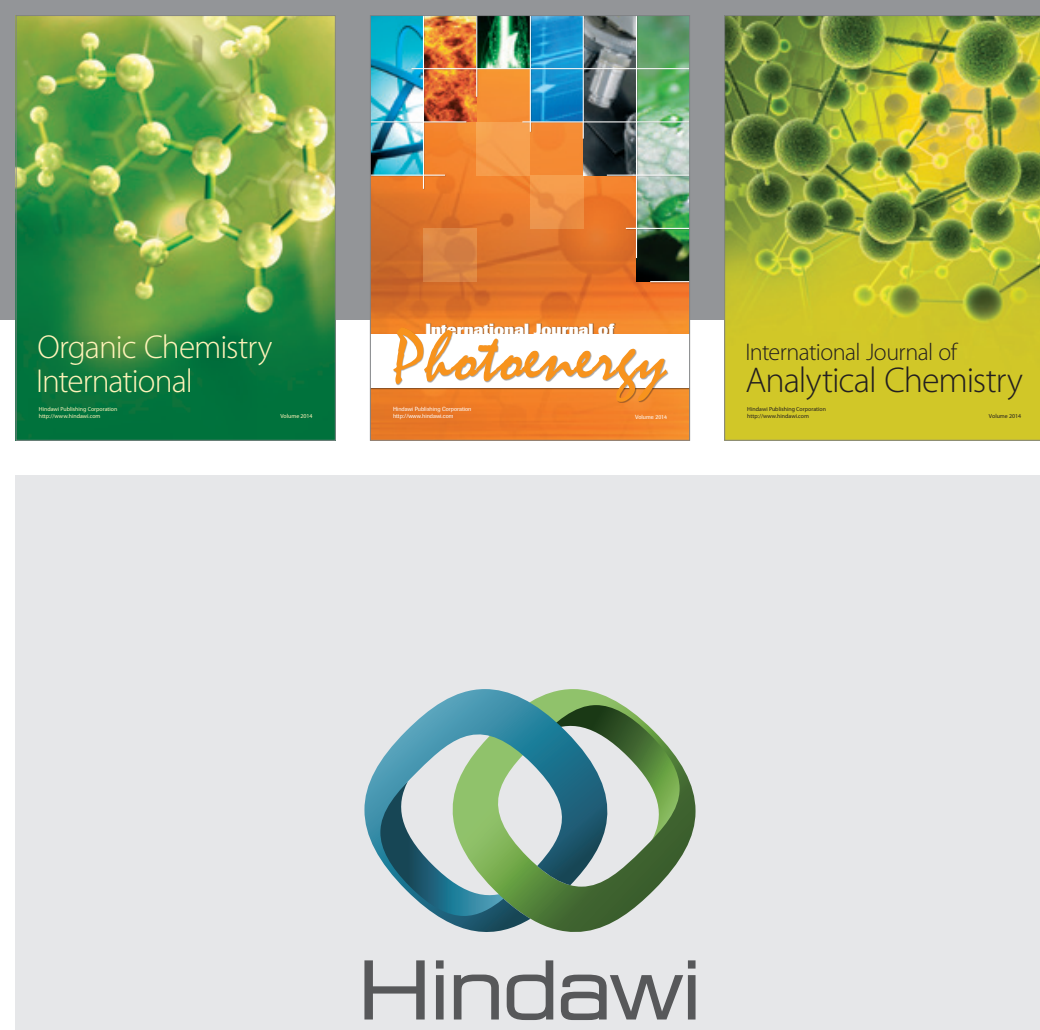

Submit your manuscripts at

http://www.hindawi.com
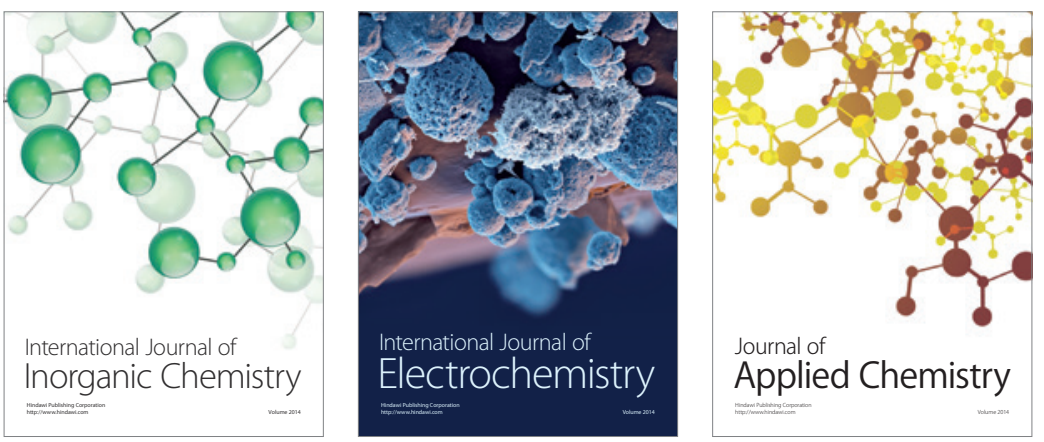

Journal of

Applied Chemistry
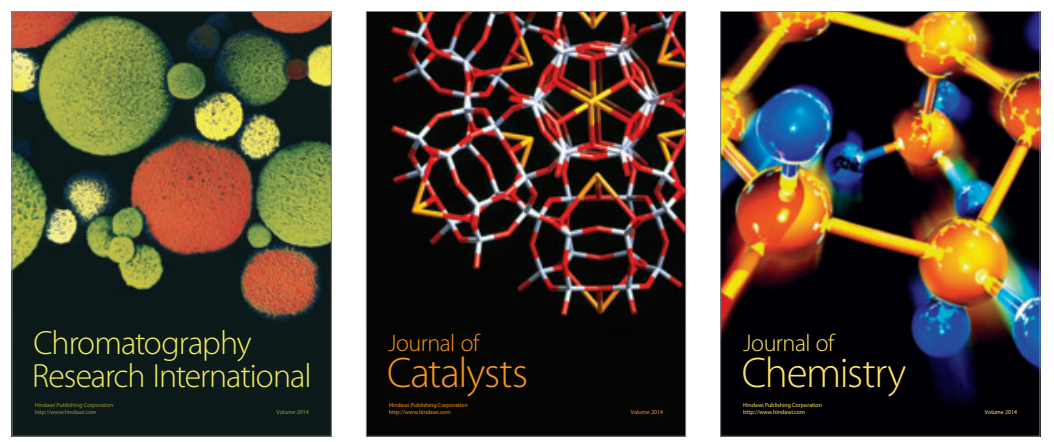
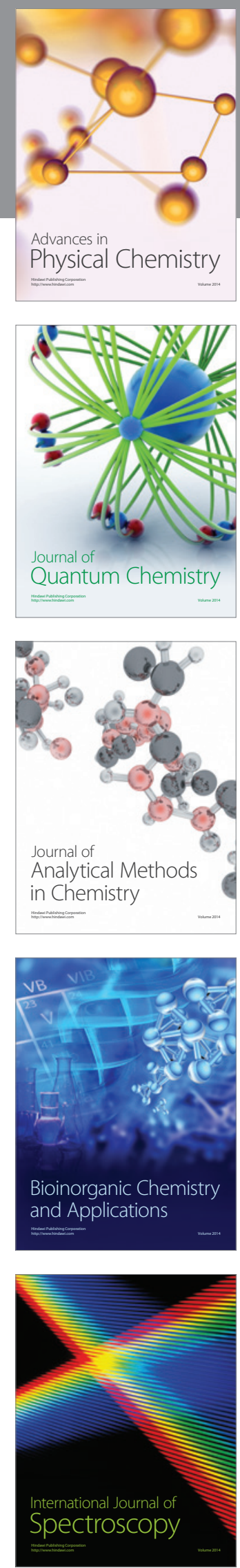